\title{
Obstacles to Lower Environmental Impact in Low-Cost Behaviors
}

The previous chapters focused on measuring the overall greenhouse gas (GHG) output, the factors that shape an individual's total emissions and different patterns of energy consumption. This chapter ${ }^{1}$ turns toward the gap between environmental values and behaviors as well as the obstacles in lowering one's environmental impact. Special emphasis is placed on "low cost behaviors" in the areas of mobility and consumption.

A gap between attitudes and behaviors is quite common. The Eurobarometer 2008, for example, reports that a total of $96 \%$ of respondents from all European countries consider environmental protection to be of great importance (64\% very important and 32\% quite important) and that $75 \%$ say they are "willing to buy environmentally friendly products even if they are a bit more expensive" (Spezial Eurobarometer, 2008, p. 12 and pp. 29ff). However, only 17\% of the respondents actually bought more eco-friendly products despite their higher price in the month before the survey. This chapter thus looks into the question of which obstacles impede consistent environmentally conscious action. This question will be addressed using a mixed-methods approach, exemplified by two environmentally relevant behaviors, consumption, and mobility. Finally, guidelines for action and policy measures to promote environmentally friendly behavior will be proposed.

\footnotetext{
${ }^{1}$ Lead author: Beate Klösch. This chapter is a continuation of the lead author's MA thesis.
}

(C) The Author(s) 2022

M. Hadler et al., Surveying Climate-Relevant Behavior, https://doi.org/10.1007/978-3-030-85796-7_7 


\subsection{Theoretical Approaches to Inconsistencies in EnVIRONMENTAL BeHAVIOR}

An inconsistency between a person's attitude and behavior is known in the scientific discourse (Blake, 1999; Brown \& Sovacool, 2018) as the valueaction gap (or attitude-behavior gap). Scientific findings indicate a demonstrable discrepancy between personal attitudes and actual behavior, especially regarding environmental actions. As early as 1999, Blake applied the concept of the value-action gap within an environmental context. Since then, this discrepancy has been proven in numerous studies on different behaviors (such as avoidance of generating refuse, recycling behavior, or the purchase of environmentally friendly vehicles) and different countries (Barr, 2004, 2006; Chung \& Leung, 2007; Hadler et al., 2019). A number of studies can also be found regarding the reasons for the occurrence of the environmental value-action gap (see Blake, 1999; Kollmuss \& Agyeman, 2002; Neugebauer, 2004; Mairesse et al., 2012; Chaplin \& Wyton, 2014). Blake (1999) identifies individual barriers, a sense of responsibility and practical feasibility as primary obstacles to pro-environmental behavior. Kollmuss and Agyeman (2002) also distinguish similar barriers, including internal factors (motivation, environmental knowledge, values, and responsibility), external factors (institutional, economic, social, and cultural factors), and socio-demographic factors (gender and number of years of education). As an explanation for the occurrence of a valueaction gap, Neugebauer (2004) also mentions internal conflicts of objective caused by the presence of competing behavior-relevant attitudes of a person as well as habits or stress.

From the literature reviewed, three main insights emerge. First, environmental behavior and the value-action gap are complex phenomena and depend on a variety of factors. Second, in several studies, intention proved to be a particularly meaningful predictor of environmental behavior, in some cases even more valid than attitudes (Barr, 2004, 2006; Ajzen, 2012). Third, most of the studies reviewed refer to the Theory of Planned Behavior (Ajzen, 1985), mentioned in Chap. 2. As it is one of the most widely used theories to explain environmental behavior and reflects the central factors of this analysis, it is also used as a theoretical framework in this chapter. This concept attempts to predict behavior using the parameters of attitude, norm, behavioral control, and intention. A central aspect is that attitudes, norms, and perceived behavioral control do not directly determine a person's behavior, but rather first influence personal 
intention, which ultimately shapes our behavior (Ajzen, 2012; Chao, 2012). If one or more of the three initial elements (attitude, subjective norm, and behavioral control) are not congruent with the intention, or the intention is not congruent with the actual behavior, a gap arises between these factors. In previous studies, however, the focus has primarily been on attitude and behavior, while little attention has been paid to intention. Therefore, intention will be included in this work, making value-intention or intention-action gaps possible.

The Framework of Environmental Behavior (Barr, 2004), which comprises a similar structure to that of environmental behavior, is further considered to complement the Theory of Planned Behavior. Barr additionally incorporates situational factors (social context, socio-demographics, knowledge, experiences, and possibilities of execution) as well as psychological factors (motivation, subj. Norms, and self-efficacy) (see Barr, 2004, pp. $234 \mathrm{f}$.). Based on these two theoretical concepts, a simplified linear model is used in this chapter, which depicts all the variables examined in the first empirical step. It is assumed that personal attitudes toward environmental problems and environmentally relevant behavior influence one's intention, which in turn shapes the behavior actually carried out. However, it must be anticipated that there may be deviations in the behavioral prediction and thus gaps between attitude, intention, and behavior. Since it is as of yet unclear whether these discrepancies occur between all three variables (i.e., between either attitude and behavior, attitude and intention, or intention and behavior) or whether the gap can only be observed between two of them, the theoretical model remains openly framed.

Finally, the low-cost hypothesis of environmental behavior (Diekmann \& Preisendörfer, 1998), which was also presented in Chap. 2, is used to determine the behaviors to be studied. It describes humans as rational actors, the homo oeconomicus, who make decisions based on cost-benefit assessments. Accordingly, the importance of one's own environmental attitudes decreases, even among particularly eco-conscious individuals, when effort or costs rise (Diekmann \& Preisendörfer, 2001; Preisendörfer, 1999). The focus of this chapter is on two behavioral dimensions with high environmental impact-mobility (kilometers driven by car per year) and consumption (new purchase of particularly $\mathrm{CO}_{2}$-intensive products). These behaviors were chosen because of their low-cost character, and research thus would predict a strong congruence. Secondly, these two behaviors are particularly $\mathrm{CO}_{2}$ intensive. By analyzing these two 
behavioral dimensions, both of which can be carried out and changed by the individual without high costs, comparisons between similar environmental behaviors become possible. In addition, fields of action open up to promote environmentally friendly low-cost and high-impact behavior.

\subsection{Identifying Value-Intention-Action Gaps in Our Sample}

The current analysis of value-intention-action gaps uses the dataset described in detail in Chaps. 4 and 5. The research questions focus on whether and which of the aforementioned gaps can be detected and for which subjects they are more likely to occur. Environmentally relevant gaps are defined as the discrepancy between attitudes or intentions and actual behavior. In Table 7.1, such a gap is exemplified by the intentionaction gap in mobility and consumption. According to this, about $15 \%$ of the respondents have a high intention to act in an environmentally friendly way but still travel many kilometers by car per year (median split). As for consumption, over $22 \%$ of the survey respondents act against their high environmental intention and show a high consumption of $\mathrm{CO}_{2}$-intensive products.

All three types of initially possible gaps ${ }^{2}$ are present in our data (in $10-35 \%$ of the sample). The centerpiece of this study, however, is the gap between a "high reduction intention" and a "high usage," which is highlighted in Table 7.1. Respondents show value-action and intention-action gaps more frequently in consumption than in mobility. According to this, individuals may find it more difficult to implement their environmentally positive attitudes and intentions in their consumption behavior than in their mobility behavior although both behaviors concern low-cost situations that could be shaped quite easily by actors.

Based on multiple regression analyses, some significant differences depending on socio-demographic characteristics, especially regarding

\footnotetext{
${ }^{2}$ Given that the regression analysis for the value-intention gap was not significant, it seems that there are no socio-demographic differences in the probability of occurrence of a gap between attitude and intention for the overall population. Thus, it appears that positive environmental attitudes translate equally into correspondingly consistent intentions to protect the environment. Accordingly, consistency does not seem to fail at the transition from attitude to intention, and individuals intend to change their behavior based on their environmental attitudes. Only when transferred into actual behavior do group-specific differences seem to occur.
} 
Table 7.1 Intention-action gap in mobility and consumption

\begin{tabular}{lccccc}
\hline Actual car use & \multicolumn{2}{c}{ Intention to change } & Actual consumption & \multicolumn{2}{c}{ Intention to change } \\
\hline & Low & High & & Low & High \\
\hline Low & $31.6 \%$ & $33.7 \%$ & Low & $23.3 \%$ & $26.7 \%$ \\
High & $19.9 \%$ & $14.8 \%$ & High & $27.7 \%$ & $22.3 \%$ \\
\hline
\end{tabular}

$N=196$

Source: OeNB sample (Hadler et al., 2021)

value-action and intention-action gaps, were identified. Age, residential area, and household constellation proved to be particularly influential. Put together, younger respondents, individuals living in rural areas, and families with children under 18 and high income are more likely to show a discrepancy between their attitudes or intentions and their behavior. Therefore, the focus of this subsequent qualitative study is on the obstacles that inhibit the environmentally responsible behavior of these groups.

\subsection{An In-Depth LoOK at OBstacles \\ to Environmentally Friendly Behavior and Solutions}

"At first sight, the nature of a value-action gap suggests either hypocrisy or non-understanding, however [...] the situation is more complex" (Chaplin \& Wyton, 2014, p. 204). The central question thus is to identify the reasons for the discrepancies between attitude, intention, and behavior, especially among individuals of different age, place of residence, and household constellation. The following sections present the results from qualitative semi-structured interviews, with participants selected based on the quantitative results presented in the previous section.

The following two conditions were found to be important for recruiting the sample: the respondents should have a positive attitude toward environmental issues, and they should own a car or at least use one regularly. Furthermore, an even distribution of the relevant socio-demographic variables (residential area, age, and household type) was aimed for: A total of 15 interviews were conducted with 16 respondents (one of which was with a couple); seven of the interviewees are women and nine live in rural areas. Furthermore, an age distribution from 23 to 68 years was achieved. For later analyses, the sample was divided into younger (23-36 years, 7 in 
total) and older (49-68 years, 9 in total) respondents. Regarding household constellations, the sample was divided into three groups, as follows: four single households, four family households with children, and seven multi-person households. Multi-person households mainly include couples as well as shared apartments with friends and living with a parent. For the following analyses, the household form is categorized in two different ways - first, depending on the presence of children (4 persons with children, 11 without), and secondly, depending on the number of people ( 5 singles, 10 partnerships/shared flats/with a parent). ${ }^{3}$

Following Mayring's method of qualitative content analysis, the interviews were inductively coded and analyzed. Due to the large amount of data, the focus is placed on the following three areas:

1. Obstacles to environmentally friendly behavior: Why do individuals not act in an environmentally friendly way but rather contrary to their eco-friendly attitudes?

2. Individual requirements: What would the interviewees wish for/ what would be necessary to make it easier for them to act in an environmentally friendly way in their daily lives?

3. Social strategies: How would people change their actions toward a more environmentally friendly way?

These three questions come into focus as they all explore the cause of value-intention-action gaps and provide suggestions for solutions.

\subsection{ObSTACLES to ENVIRONMENTALly FRIENDLY BEHAVIOR}

First, obstacles to environmentally friendly action mentioned in the interviews were analyzed and coded. A total of 16 codes resulted, which can be categorized into two dimensions of structural and intrapersonal factors. Structural conditions mainly include situational factors, such as the limited availability of goods and services, lack of information, and time and cost factors. Intrapersonal factors are obstacles at the individual level, such as convenience, routine, or lack of interest.

\footnotetext{
${ }^{3}$ It should be noted that due to the uneven distribution of group sizes regarding household constellation (both in terms of the number of people living in the household and children), the interpretability of the results is limited.
} 
Time and cost factors of environmentally friendly alternatives prove to be the most influential structural framework conditions. Especially high prices for public transport and higher pricing of sustainable clothing or biological food, compared to conventional products, were often emphasized. The time factor frequently refers to public transport, which, on the one hand, often requires a long wait, and, on the other hand, usually takes longer than if one were to travel by car. Higher costs of public transport were also often mentioned. In combination with the time required, it was also mentioned that eco-friendly actions are often cumbersome (be it in terms of consumption, when you have to visit ten shops to find all products of organic quality, or be it concerning mobility, where the use of public transport with children, heavy luggage, etc., is too much of a hassle). The fundamental lack of environmentally friendly products on offer, such as in clothing, was also a frequently cited obstacle for not acting in an environmentally friendly way.

To conclude, for many of the interviewees, the availability of ecofriendly alternatives such as clothing and public transport is not sufficient, and the existing supply is often expensive or involves a lot of effort. Another obstacle is the lack of information or knowledge about more environmentally conscious alternatives. All in all, information is lacking at several points. First, there must be information or knowledge about which behaviors are harmful to the environment and that there are alternatives. Secondly, there is often a lack of information on what these alternatives look like. And third, there is a lack of information on where these alternative products (e.g., in regional or sustainable quality) are available. This shows that despite the individual willingness of the interviewees to inform themselves, there is a lack of clear and public information that can contribute to a more environmentally friendly behavior. Another factor that was mentioned several times is the credibility of eco-friendly products. Several interview partners reported that they are often not sure which is the better alternative or that they have limited trust in certifications, labels, and the like. One interviewee commented on this as follows:

I sometimes have the feeling that just because it says organic somewhere, it doesn't necessarily have to be organic in the classical sense, or just because it says sustainable products or sustainable materials [...] So I still bave the feeling that loopholes are found or made, and people just take it along or offer it, because that's the way it is now. [...] So for me it would be very important that people know that they can rely on it if it says so. 
The most influential intrapersonal obstacle to environmentally friendly behavior is the convenience of those interviewed. This affects both the search for information on eco-friendly offers and actually carrying out the behavior. This was often explained by the attempt to avoid undue effort (e.g., doing the shopping by public transport). Routine and habit were also frequently cited as reasons why interviewees did not make use of environmentally friendly options. In addition, the lack of consistency in one's own actions was mentioned a few times, and environmentally harmful behavior, especially in the area of consumption, was justified by frugality. This applies in particular to the purchase of new clothing by men.

Some links between structural and intrapersonal factors also emerge. In particular, the time factor was often mentioned together with personal comfort level and the inconvenience of environmentally friendly alternatives as a barrier to eco-friendly behavior. There also seems to be a connection between the cost factor and convenience, similar to the lack of supply. Routine also frequently occurs together with the time factor as well as the lack of supply.

A comparison of the barriers for the two behaviors, mobility and consumption, reveals some obstacles that occur in both. Commonalities occur regarding time and cost factors, convenience, and lack of supply. However, the time factor and convenience act as barriers to environmentally friendly behavior more often in the context of mobility than in consumption. Factors that have no effect on mobility behavior but that inhibit environmentally friendly consumption behavior are especially lack of information, no clear labeling of eco-friendly products or doubts in the credibility of existing labels as well as a lack of consistency in using environmentally friendly products.

Subsequently, the reasons for the occurrence of value-intention-action gaps were analyzed in relation to influential socio-demographic characteristics, specifically, place of residence, age, and household structure. With regard to place of residence, there is definitely a difference in obstacles to environmentally friendly behavior between respondents living in rural areas and those living in the city. The dependence on place of residence was mentioned several times by interviewees in rural areas, whereas it was not mentioned by urban dwellers. The statements in this regard vary from a lack of public transport connections, a smaller range of stores/options, and so on to financial advantages since regional fruits and vegetables can be purchased more cheaply at the rural farmers' market than in the city. Nevertheless, it is evident that individuals living in rural areas are more 
aware of their location's dependency and the resulting barriers than those living in the city. Cost and time factors were also mentioned more frequently in rural areas than in the city, as were high costs and lack of options (especially when it comes to clothing) and information as well as individual lack of consistency. In comparison, respondents in the city more often mentioned their habits and routines as a reason for a lack of environmental behavior.

There is one barrier that was only mentioned by older interviewees, namely forgetting or not thinking about more environmentally friendly alternatives. An older interviewee said,

I have difficulties remembering to take a box with me when I go shopping, like it was done in the 80s. We did all that before, and somehow it completely dropped off in the 90s. And no one went shopping with their own dishes anymore. And to think of that again.

Furthermore, older individuals mentioned more often the lack of information and the cost factor than younger ones. The latter seem to see greater problems in the time factor (especially concerning public transport) and their convenience.

There are also some differences between households. Comparing single- and multi-person households shows that forgetting or not thinking about eco-friendly alternatives was only mentioned in multi-person households. In addition, respondents living with more than one person also mentioned convenience, cost, and time factors, as well as lack of information as reasons for their partial lack of pro-environmental actions. Furthermore, some reasons were only mentioned by respondents without children. These were general structural conditions and the lack of labeling of environmentally friendly products. On the intrapersonal level, respondents without children mentioned a lack of interest in learning more about eco-friendly options as well as frugality in certain areas. Surprisingly, the interviewees with children in their household did not mention any reasons that are not equally common in childless households.

Overall, a complex interplay of numerous reasons for the emergence of value-intention-action gaps can be identified. A comprehensive intervention program seems to be needed that promotes environmentally friendly behavior in all areas, both on the individual and on the societal levels. This view is further examined in the following sections based on the statements of the interviewees. 


\subsection{Individual Requirements to Facilitate EnVIronmentally Friendly Behavior}

After knowing why it is often not possible for the interviewees to choose environmentally friendly alternatives and behaviors, this section looks into what they would need or wish for to make it easier to act in an environmentally friendly way.

The respondents most frequently wished for more information on environmentally friendly products and a stronger presence of environmental issues in the public discourse. Information on what is actually eco-friendly and what options and offers are available is desired. According to the interviews, the mobility sector also seems to be particularly expandable. The interviewees frequently wished for better public transport, which concerns the geographical expansion of these as well as more frequent connections (including evenings and weekends). Public transport should also be cheaper, and reference was made to pay structures such as in Vienna (€l per day). Alternatives were also mentioned, such as a planned regional train project or e-car sharing offered by the municipality. In the area of consumption, the interviewees often wished for better labeling of environmentally friendly products, such as through a unified seal or through signs in shops. This wish was expressed several times for both clothing and food, and some suggestions for implementation came from the respondents themselves (labeling by, e.g., green tick, environmental calories, and/or $\mathrm{CO}_{2}$ footprint on each product). One respondent expressed the following:

Maybe on top of packaging, it would be quite a good idea, because everyone knows the table with calories and nutritional value, but maybe also such an ecological table that you just know how many liters of water were used for the production of that product, from the beginning to the end. Simply how many liters of water were used, how many tons of $\mathrm{CO}_{2}$ were emitted, for that piece you bave there.

There also seems to be a big deficit in the availability of environmentally friendly products in both rural and urban areas. The respondents would like to see a larger and regional range of food (preferably a shop where you can get everything at once), more packaging-free shops and a larger range of sustainably produced clothing. There appears to be a backlog here, especially for men's clothing and fashionable items. Several respondents would also like to see better support for environmentally friendly projects, 
be it independent fashion shops or so-called environmental banks. One interviewee talked about such a bank that only gives loans to regional organic farmers. Others would also like to see more financial support from the municipality for local shops.

Finally, individual requirements to facilitate eco-friendly behavior were also considered with respect to dependencies on the socio-demographic characteristics of place of residence, age, and household constellation. Regarding the place of residence, it can be shown that only respondents living in rural areas would like to have reduced public transport fares and other cheaper alternatives in the context of consumption. Thus, the cost factor seems to play a greater role in rural areas than in cities. With regard to age, there are only minor differences among individual requirements. There is a tendency that younger individuals would like to see a wider range of clothing and other environmentally friendly products and their labeling as well as a better range of public transport. Concerning the household type, it appears that respondents from a multi-person household would like better public transport as well as a wider range of ecofriendly products such as for food. These factors were not mentioned in the single households. Furthermore, the former group tends to require more information on and the presence of the topic in the public discourse, better labeling of products, funding of environmentally friendly projects, and a wider range of clothing and public transport, as well as cheaper public transport fares than do respondents living on their own. Likewise, respondents without children in the household would like to see cheaper alternatives, which were not mentioned by respondents with children in the household. Otherwise, respondents without children tended to wish for more information on and the presence of the topic in daily life and a broader offer with better labeling as well as discounts on public transport.

\subsection{Social Strategies to Promote Environmentally Friendly BeHAVIOR}

After discussing subjective obstacles to environmentally friendly behavior and individual requirements to facilitate the implementation of ecofriendly alternatives, this section takes a brief look at what is needed, according to the interviewees, to achieve a change in behavior in society as a whole. The interview participants most frequently saw potential for social change among the population through education and raising 
awareness about the climate crisis. The problem of lack of information was also mentioned several times:

I think for many people the problem is often the beginning because they don't know how or where. How can I change something, where ...? And there we come to the next issue, the flow of information. That somehow you would have to teach or explain that to people like that ... the education.

According to the interviewees, more information and education should be provided through the media, through targeted advertising and famous personalities acting as role models (such as Greta Thunberg, Arnold Schwarzenegger, influential politicians, or athletes). Equally important and necessary for the interviewees is the introduction of regulations and prohibitions by policymakers, both for individuals and for large players, such as companies. One interviewee formulated this point as follows:

\section{Unfortunately, I think it is important for the majority to have bans. Yes, per- sonal freedom is also important, but I think that when it comes to such a topic that simply affects us all and where the effects are so massive, and where science has been warning for a long time and somehow, we don't manage to change behavior simply because of a raise in awareness, then I have the feeling that you have to force people to do it.}

Outside the individual level, guidelines for companies and policies regarding the transportation sector as well as legal regulations, such as for packaging, are desired. Sanctions should be enforced in cases of noncompliance with the given laws. This includes the introduction of a $\mathrm{CO}_{2}$ tax or kerosene tax for air traffic. The interviewees see another influential factor in schooling - the necessity of implementing environmental topics and knowledge in schools as well as the discussion of consequences and alternatives was mentioned several times, as children would in turn pass this awareness on to their families. Finally, some respondents also consider a systemic change to be necessary in order to counter the climate crisis. Here, a change in values away from current mass consumption is emphasized. According to the respondents, a rethinking of what quality of life means is needed, including in the context of work and leisure. Other solutions that were brought up repeatedly are, on the one hand, a development toward more regionality and the need for environmentally conscious lifestyles without any feelings of restriction. Such normality should be 
conveyed through school and should find its way into the personal sphere, especially the family, and become part of the habitus. It was also mentioned a few times that an environmentally friendly lifestyle must become more attractive. It should become financially as well as personally attractive, stand for a better quality of life, and be considered a status symbol. Finally, it can be concluded that the interviewees see the greatest potential in political guidelines and bans as these offer the opportunity to exert influence on daily actions of both individuals and larger entities such as companies on many different levels.

\subsection{Discussion of Obstacles to EnVironmentally Friendly Behavior and Potential Solutions}

In summary, the analysis of the interviews shows that time and cost factors (structural reasons), as well as convenience and routine (intrapersonal reasons), were the major obstacles to consistency between attitude, intention, and behavior in regard to environmentally friendly behavior. This finding also coincides with previous results from the literature, such as with the individual and practical barriers found by Blake (1999). However, taking responsibility and perceiving one's own actions as effective do not seem to be a problem for the interviewees in this study. Almost all agreed that the contribution of individuals (in addition to political framework conditions) is crucial to counteract the climate crisis. Likewise, Kollmuss and Agyeman's (2002) "Model of Pro-Environmental Behavior" includes some factors that were confirmed here as barriers to pro-environmental action. In particular, the lack of external opportunities such as infrastructure, economic situation, and political conditions, as well as old habits of action, seems to have negative effects in the sample. The internal factors predicted by Kollmuss and Agyeman, such as personality traits or lack of environmental awareness, appear to be less substantial in this study.

The qualitative approach allows us to delve deeper into the (dis)similarities between environmentally relevant mobility and consumption behaviors. In this respect, it can be concluded that, contrary to the theoretical assumption, discrepancies between attitude, intention, and behavior can also occur in environmentally related low-cost behaviors, which can be explained to a large extent by the obstacles found in the present analysis. The respondents face the same barriers in both behaviors (e.g., time and cost reasons and lack of supplies) but also behavior-specific 
obstacles such as the lack of labeling of eco-friendly products. For the mobility realm, factors of time, cost, and convenience were particularly inhibiting. These results are in line with the findings of Diekmann and Preisendörfer (see Diekmann \& Preisendörfer, 2001, p. 73) as well as with the assumption of the rational choice theory that these very factors have the greatest influence on behavior, for example, in the choice of means of transport, especially in the context of mobility (see Götz, 2011, p. 334). The results of this study suggest that it would often be possible to switch to public transport but that this is often not done due to the reasons mentioned above. This problem could potentially be addressed with appropriate (e.g., financial) incentives and motivators to reduce the costs of engaging in eco-friendly behavior.

In comparison, considerably more obstacles were found regarding consumption behavior. The large number of possible barriers in consumption could explain why, according to the quantitative results, discrepancies occur more frequently here than in the mobility realm. In the context of consumption, eco-friendly behavior could be supported in particular by improving the structural conditions in terms of supply and labeling. It seems that personal environmental attitudes and existing intentions are often not enough to encourage environmentally friendly behavior even if the situations are theoretically low-cost and individuals could easily adapt.

Furthermore, respondents in rural areas are confronted with different obstacles than those living in cities, especially considering the availability of alternatives to private cars, clothing, and other eco-friendly products. The cost factor is also a greater obstacle in rural areas than in cities. This may be due to different reasons. On the one hand, environmentally friendly alternatives in terms of mobility and consumption may actually be cheaper in cities as there is more choice there. It can be assumed that this is especially the case for public transport, which is cheaper as well as better developed in cities. On the other hand, this perception could possibly also be due to the sample and the distribution of socio-demographic variables such as age and income (the individuals living in cities tended to be younger; no data are available on income). Nevertheless, it should be noted that due to location dependency, the precondition that actions must be objectively possible is often not met in rural areas (see Tanner \& Foppa, 1996, p. 246). It can be concluded that a low-cost behavior can become a high-cost behavior depending on the place of residence. Finally, it is the individual's "definition of the situation" that matters; as Diekmann and Preisendörfer sum up: it is about the perception of alternative actions, the 
assessment of the occurrence of consequences of actions and the perception of costs and benefits of the consequences of actions (see Diekmann \& Preisendörfer, 2001, p. 76). Accordingly, environmentally friendly behavior is often more cost-intensive in rural areas than in cities, which subsequently leads to a more frequent occurrence of discrepancies between attitude, intention, and behavior in rural areas.

Moreover, older respondents reported that they often do not think about or forget about more environmentally friendly alternatives. One explanation for this could be the decades of routine in everyday activities such as grocery shopping. Regarding the household constellation, interviewees from multi-person households reported problems with convenience and lack of information as well as time and cost factors. One could conclude here that single households have more money and time available to choose more eco-friendly alternatives. Another explanation could be the increased obligations that additionally influence individuals in multiperson households in their decisions to act. However, respondents with children do not seem to face any additional obstacles. It can be concluded that multiple obligations, such as raising children, do not provide additional obstacles to environmentally friendly behavior that do not also occur in persons without children. Thus, the results of the quantitative study that people with children more often have a value-intention-action gap cannot be adequately explained through these interviews.

In summary, a large number of barriers to environmentally friendly action was found both on the structural and intrapersonal levels. The results show that, often, several obstacles exist at the same time when there is a discrepancy between one's attitudes, intentions, and behavior. Accordingly, two birds could be killed with one stone here, for example, by counteracting the intrapersonal factors such as convenience and routine by creating attractive offers and a better flow of information on the structural level.

Finally, some individual needs and societal solutions could be worked out. On the individual level, better availability of public transport and a wider choice of eco-friendly alternative products as well as their unified and clear labeling were often considered necessary. The desire for the normality or self-evidence of environmentally friendly products and behaviors as well as an accompanying reduction of the offer of environmentally harmful options was also mentioned repeatedly. Thus, there seems to be a need for action, especially at the structural level, which was also reflected in the social strategies and potential solutions proposed by the 
interviewees. To induce a change in behavior in society, the interviewees see a necessity in political measures, regulations, and bans. These regulations should be enforced with the help of sanctions or a corresponding $\mathrm{CO}_{2}$ tax. Equally relevant to the interviewees seems to be a stronger education of the population to create greater awareness of nature and its protection. This should begin in early education and, if necessary, also be promoted on an institutionalized level in the form of environmental school lessons. In this context, the importance of eco-positive role models was also emphasized, through which young people can orientate themselves. Following this, on both the individual and societal levels, it was frequently mentioned that more information is needed to strengthen environmentally friendly action and to circumvent any related obstacles. This was described by two interviewees as follows:

I thought it would be cool if it was somehow explained in detail on their homepage or if there was a video about what exactly needs how many resources. Just more information. So, for me, it always helps quite a lot if I know something about it, so that I then decide in favor of the alternative, even if it is perbaps inconvenient.

Well, it's shocking, but if you publicize the whole thing, people will certainly think about it. And science is particularly important in my eyes, that they show the whole thing, what effects it has: Because then you will certainly be able to reach more people.

However, scientific discourse and the dissemination of information on climate change were found to be ineffective in changing opinions. Rather, opinions were reinforced by the information communicated due to selective information processing. According to Moser and Berzonsky, a "louder one-way messaging will only add to polarization rather than reduce it" (Moser \& Berzonsky, 2015, p. 17), which is why they emphasize the need for individual motivation and willingness to act for the environment. Thus, other potential solutions should be considered more closely.

With regard to the differentiation between attitude and intention, no clear findings can be derived from the interviews. In general, it can be assumed that most of the interviewees have both positive environmental attitudes and the willingness to change their own behavior for the environment. According to the statements, this often fails due to a lack of options for action and offers, which ultimately lead to an intention-action gap. Only a few respondents stated that they have no interest in specific 
topics and thus no intention to change their behavior. However, this only concerns a few older men when they were asked about their consumption behavior in terms of clothing. They also justify their lack of interest through their lower consumption of clothing. Thus, the value-intention gap, which already played only a minor role in the quantitative analyses, is also to be expected here only to a very small extent and under certain circumstances.

\subsection{CONClusions and Outlook}

The aim of this chapter was to understand why environmentally conscious individuals nevertheless fail to behave in an environmentally friendly way. The quantitative analysis showed that individuals find it more difficult to behave consistently with their attitudes and intentions in the context of consumption than in that of mobility. The qualitative interviews highlight that individuals are most often deterred from the desired behavioral practice by intrapersonal factors (such as their own convenience or habits) and structural conditions (such as time and cost factors, lack of offerings).

These findings are mostly in line with the results of other studies. Regarding the obstacles to eco-friendly behavior, many elements from the "Model of Pro-Environmental Behavior" by Kollmuss and Agyeman were confirmed, specifically, the importance of structural conditions as well as routines and habits for pro-environmental behavior. The importance of situational factors is also in line with Barr's "Framework of Environmental Behavior."

As for the question of how to promote environmentally positive behavior in society, the interviewees considered two steps to be particularly necessary-on the one hand, there is a need for increased education, information dissemination, and awareness raising among the population in order to counteract intrapersonal barriers. These can be promoted through implementation in school lessons or via media and advertising, which should eventually lead to a change in lifestyle, away from consumption, as well as a normality of environmentally friendly behavior.

On the other hand, at the structural and political levels, a change in market regulation is desired, especially with regard to the offering and promotion of eco-friendly alternatives. Likewise, a restriction on environmentally harmful products and behaviors should be aimed for, both through bans and associated sanctions as well as $\mathrm{CO}_{2}$-related taxes. Hence, a whole range of design proposals can be derived from the interviews, such 
as one unified and credible label for pro-environmental products, an indication of environmental or " $\mathrm{CO}_{2}$ calories" depending on the $\mathrm{CO}_{2}$ emissions for each product, and a $\mathrm{CO}_{2}$ app that documents daily consumption and introduces alternatives in a playful way.

There were also numerous calls for action in the interviews, which should be heard above all at the political level. Although each of the interviewees considered the individual's contribution to environmental protection to be essential, there was consensus that policies need to provide structural conditions in order to exploit the full potential. The concluding chapter will thus consider some of these suggestions in an international comparative analysis and test their effectiveness.

\section{REFERENCES}

Ajzen, I. (1985). From intentions to actions: A theory of planned behavior. In J. Kuhl \& J. Beckmann (Eds.), Action control: From cognition to behavior (pp. 11-39). Springer.

Ajzen, I. (2012). The theory of planned behavior. In P. A. M. Lange, A. W. Kruglanski, \& E. T. Higgins (Eds.), Handbook of theories of social psychology (pp. 438-459). Sage.

Barr, S. (2004). Are we all environmentalists now? Rhetoric and reality in environmental action. Geoforum, 35, 231-249.

Barr, S. (2006). Environmental action in the home: Investigating the 'valueaction' gap. Geography, 91(1), 43-54.

Blake, J. (1999). Overcoming the 'value-action gap' in environmental policy: Tensions between national policy and local experience. Local Environment, $4(3), 257-278$.

Brown, M. A., \& Sovacool, B. K. (2018). Theorizing the Behavioral dimension of energy consumption: Energy efficiency and the value-action gap. In D. J. Davidson \& M. Gross (Eds.), The Oxford handbook of energy and society (pp. 201-221). Oxford University Press.

Chao, Y.-L. (2012). Predicting people's environmental behavior: Theory of planned behavior and model of responsible environmental behavior. Environmental Education Research, 18(4), 437-461.

Chaplin, G., \& Wyton, P. (2014). Student engagement with sustainability: Understanding the value-action gap. International Journal of Sustainability in Higher Education, 15(4), 404-417.

Chung, S., \& Leung, M. M. (2007). The value-action gap in waste recycling: The case of undergraduates in Hong Kong. Environmental Management, $40(4), 603-612$. 
Diekmann, A., \& Preisendörfer, P. (1998). Umweltbewußtsein und Umweltverhalten in Low-und High-Cost-Situationen: Eine empirische Überprüfung der Low-Cost-Hypothese. Zeitschrift für Soziologie, $27(6), 438-453$.

Diekmann, A., \& Preisendörfer, P. (2001). Umweltsoziologie. Eine Einführung. Rowohlt.

Götz, K. (2011). Nachhaltige Mobilität. In M. Groß (Ed.), Handbuch Umweltsoziologie. VS Verlag für Sozialwissenschaften.

Hadler, M., Schwarzinger, S., \& Schweighart, M. (2019). Forschungsbericht. Umweltspezifische Lebensrealitäten von MaturantInnen in der Steiermark. Graz.

Hadler, M., Schweighart, M., \& Wardana, R. (2021). OeNB CO2-relevant environmental behavior. Data will be available for free at the Austrian Social Science Data Archive. www.aussda.at; https://doi.org/10.11587/WQGMKY

Kollmuss, A., \& Agyeman, J. (2002). Mind the gap: Why do people act environmentally and what are the barriers to pro-environmental behavior? Environmental Education Research, 8(3), 239-260.

Mairesse, O., Macharis, C., Lebeau, K., \& Turcksin, L. (2012). Understanding the attitude-action gap: Functional integration of environmental aspects in car purchase intentions. Psicológica, 33, 547-574.

Moser, S. C., \& Berzonsky, C. L. (2015). There must be more: Communication to close the cultural divide. In K. O'Brien \& E. Selboe (Eds.), The adaptive challenge of climate change. Cambridge University Press.

Neugebauer, B. (2004). Die Erfassungvon Umweltbewusstsein und Umweltverbalten. (ZUMA-Methodenbericht, 2004/07). Mannheim: Zentrum für Umfragen, Methoden und Analysen.

Preisendörfer, P. (1999). Umwelteinstellungen und Umweltverhalten in Deutschland. Empirische Befunde und Analysen auf der Grundlage der Bevölkerungsumfragen „Umweltbewußtsein in Deutschland 1991-1998”. Springer Fachmedien.

Spezial Eurobarometer (2008). Einstellungen der europäischen Bürger zur Umwelt. Bericht. Spezial Eurobarometer 295/Wave 68.2-European Opinion Research Group EEIG.

Tanner, C., \& Foppa, K. (1996). Umweltwahrnehmung, Umweltbewußtsein und Umwelt-verhalten. In A. Diekmann \& C. C. Jaeger (Eds.), Umweltsoziologie. Kölner Zeitschrift für Soziologie und Sozialpsychologie, Sonderheft 36/1996 (pp. 245-271). Westdeutscher Verlag. 
Open Access This chapter is licensed under the terms of the Creative Commons Attribution 4.0 International License (http://creativecommons.org/licenses/ by $/ 4.0 /$ ), which permits use, sharing, adaptation, distribution and reproduction in any medium or format, as long as you give appropriate credit to the original author(s) and the source, provide a link to the Creative Commons licence and indicate if changes were made.

The images or other third party material in this chapter are included in the chapter's Creative Commons licence, unless indicated otherwise in a credit line to the material. If material is not included in the chapter's Creative Commons licence and your intended use is not permitted by statutory regulation or exceeds the permitted use, you will need to obtain permission directly from the copyright holder. 